\title{
The Role of Explicit Teaching Remedy in Enhancing Grammatical and Lexical Cohesive Devices Problem in Second Year Students Writing' $s$ at the University of Constantine 01
}

\begin{abstract}
:
Cohesion is the use of grammatical and lexical cohesive devices to tie ideas across texts; it is also an important element for maintaining coherence in any piece of discourse. Researchers agreed that this problematic area to EFL learners; however, no curative medicine has been given yet. Therefore, this study focuses on the explicit teaching approach with the purpose of teaching different grammatical and lexical ties to second year students of English at the University of Constantine 1. An experimental design is used to test the efficacy of this approach where two experimental (EXP) and control (CTR) groups undertook the tests. After the analysis of both the pre- and post- tests scores, the results revealed that the explicit teaching is successful in solving cohesive devices problem simply because the improvements in the EXP group is far higher than those of the CTR group, though there are some aspects such as: ellipsis and substitution which have not enhanced significantly.
\end{abstract}

Keywords: cohesion, lexical and grammatical cohesive devices, explicit teaching

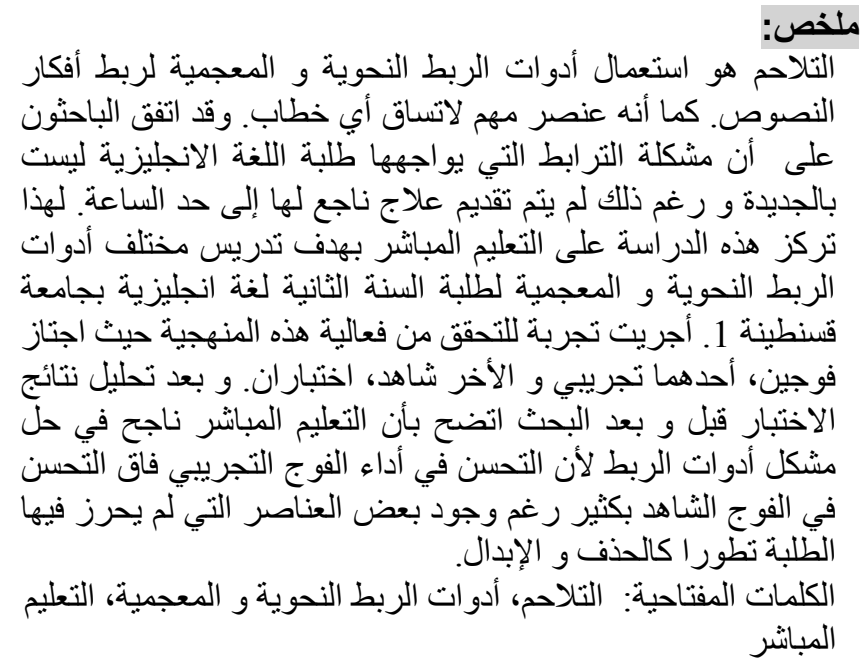

\author{
Abid Meriem \\ Faculté des Lettres et des Langues. \\ Département d'Anglais. \\ University of Mentouri \\ Constantine
}

\section{Introduction:}

Since writing is among the four skills English learners should manipulate in order to master a specific language, it is one of the most interactive ways of transferring ideas to others. However, the ability to write cohesive and coherent piece of writing is a problem even for native speakers; 
Therefore, learning how to write effectively needs a lot of practice and explicit instructions. The latter depends on explaining the different ties using various tasks, reading prompt, and selective feedback to figure out the rules of use as well as the different devices uses.

Cohesion is one of the seven standards that make a text a text; this means that it is important and useful for testing the quality of a piece of written discourse. Halliday and Hassan's work (1976) is considered as a corner stone for subsequent studies on cohesion including this one. It refers to the presence or the absence of linguistic ties to create meaning. Those ties are both grammatical and lexical and their usage may differ from one genre to another.

The purpose of the present study is to investigate the role of explicit teaching in developing cohesion in the essays written by second year students of English at the University of Constantine 1.

\section{The Nature of Cohesion}

Halliday and Hassan (1976) state that cohesion refers to the semantic relations within the text. It occurs when some elements of discourse depend on other previous elements for its interpretation - presupposition- because it enables the reader to grasp the meaning by examining the surrounding elements. For better understanding of how cohesion is achieved, we borrow Halliday and Hassan's (1976, p. 2) example: "Wash and core six cooking apples. Put them into fireproof". "Them" in the second sentence presupposes something and refers to "six cooking apples", and the reader cannot understand what "them" means without referring to "six cooking apples" mentioned in the first sentence. To Halliday and Hassan (1976, p.26) cohesion indicates whether sentences are connected; it concerns structure not "what a text means; it concerns how a text is constructed as a semantic edifice". They consider that well-structured sentences are obviously coherent, for, they contend, "all grammatical units -sentences, clauses, groups, words - are internally 'cohesive' simply because they are structured (p.7).

To Widdowson (2007, p.131) cohesion is the use of different pro-forms to link different parts of a text. He defines pro-form as "a linguistic form that stands for another expression in a text by coping some of its semantic features. Thus in the taxi has been ordered. It will be here in a minute, the pronoun it copies the features of singular/inanimate from the noun taxi.

All the above explanations state that cohesion is glue that holds a piece of discourse together. It is generally achieved through the use of clear, explicit and verifiable linguistic -grammatical and lexical-devices.

\section{Cohesion and Coherence Debate}

For a long time there was huge debate about what cohesion and coherence really mean. Some researchers used the two terms interchangeably because it is considered that the linguistic devices used to bond texts together are the main source for achieving coherence. However, recently researchers believe that the 
two concepts are separate from each other. In fact, they agree that cohesion is the use of the grammatical and lexical devices to link the different parts of the texts together. But, some difficulties occur when it comes to coherence. To Halliday and Hassan (1976) coherence refers to coherence of text in relation to context whereas cohesion has to do with coherence with the text itself. To them coherence is wide in scoop since it requires the context of the situation for its understanding.

Moreover, researchers believe that cohesion is a component of coherence. It is through the appropriate use of cohesive devices, coherence is achieved. The inappropriate use of reference in students' writings, for example, leads to incoherent texts. This is what Halliday and Hassan (1976) talk about when they consider cohesion as one component for text coherence, referring to as texture; and their position is illustrated as follows: "the texture involves more than the presence of the semantic relations we refer to as cohesion (p.23). Likewise, Oshima and Hogue (1999) state that coherence refers to the ability to read and understand paragraphs easily, and this is due to two things: the logical order of sentences and the appropriate use of cohesive devices. When this is achieved, the reader feels that the text coheres or holds together. For Hinkel (2004), cohesion refers to the connection between sentences and paragraphs and coherence refers to the organization of discourse with all elements present and fitting together logically.

\section{Taxonomies of Cohesive Ties}

Mentioning earlier that a text displays cohesion when its parts are joined through grammatical and lexical cohesive ties to give unity to the text; therefore, they are classified into two major classes grammatical and lexical. Each of which is further categorized into sub-classes.

\subsection{Grammatical Cohesive Ties}

Halliday and Hasan (1976) classified them into five distinct categories namely: reference, substitution, ellipsis, conjunctions and lexical cohesion which have further elaborated in Halliday's (1994) work into four categories with ellipsis as a subcategory of substitution. Other researchers as Zamel (1983), MaCharthy (1991), Hinkel (2004), Harmer (2004), etc add verb tense and parallelism as further aspects of cohesion.

\subsubsection{Reference}

Yule (1996, p.16) states that words themselves don't refer to anything, people do so. He defines reference "as an act in which (...) a writer uses linguistic forms to identify something". To him, reference is a word or phrase chosen to identify an object or a person in the world.

In English, references are divided into three kinds: personals, demonstratives and comparatives. A personal reference is achieved by using 
personal and possessive pronouns and possessive determiners (adjectives). A demonstrative reference is created through the use of demonstratives. A comparative reference is realized through the use of adjectives and adverbs of comparison describing likeness or unlikeness and identity between items in texts. The following examples taken from Halliday and Hassan (1976, p.31) illustrate the three kinds:

- Three blind mice, three blind mice.

See how they run! See how they run!

(The personal reference "they" refers to three blind mice)

- Doctor Foster went to Gloucester in a shower of rain.

He stepped in a puddle right up to his middle and never went there again.

(The demonstrative reference "there" refers to Gloucester)

- We have received exactly the same report as was submitted two months ago.

(The same refers to the reported report before two months, since comparison is a form of reference).

\subsubsection{Substitution}

It is agreed that substitution is a relation of replacement of one linguistic item by another. It is used to avoid repetition of particular items. For example:

1. My axe is too blunt. I must get a sharper one.

2. You think john already knows? I think everybody does.

"One" and "does" are examples of substitution in the sense that "one" substitutes "the axe" and "does" "knows".

There are three kinds of substitution, taken from Kenndy (2003, p.324): nominal substitution replaces a noun or noun phrase with "one", "ones", or "the same" like in: I have ordered a black coffee. Do you want the same? Verbal substitution replaces a verb with a 'pro-form' using the auxiliary "to do" such as: Paul likes muffins. Sara does too. Clausal substitution uses a pro-form "so" or "not" to replace a clause as in: (1) I went to the exhibition and so did Fred. (2)I went to the pictures, and Jane did too. (3) Has he fixed the window? I (don't) think so. If not, I'll ring him again.

\subsubsection{Ellipsis}

Ellipsis is the omission of some elements in the text. It is a kind of substitution with nothing or with zero. Like substitution, ellipsis is a relation of meaning at the lexicogrammatical level. Like substitution, ellipsis has three main contexts for its occurrence clausal (e.g. a: Can you row? b: Yes. [I can row]), verbal (e.g. a: Does it hurt? b:Not any more ) and nominal (e.g.a:Take of your hat.b: It is not mine. [my hat]).

\subsubsection{Conjunctions}


To Halliday and Hassan (1976) conjunction is a type of grammatical cohesion used to link ideas together semantically, and what follows is related to what comes before. Those relations are achieved through the use of coordinating conjunctions, subordinators, adverbials and certain prepositional phrases. They clarify that there are different classifications of conjunctions but they mentioned only five types: additive (and also, furthermore, in other words, likewise...), adversative (however, in fact, instead, in any case,...), causal (so, because, otherwise, in this respect,...), temporal (after that, soon, next, up to now,...) and other conjunctions (well, of course, anyway, surely,...). They also argue that within conjunctions as a cohesive device, the focus is not on the semantic relations but on the function they have when relating the linguistic elements.

\subsubsection{Verb Agreement}

Zamel (1983) states that tense can signal relationships within texts and helps in creating cohesion. Similarly, Hamer (2004) and Hinkel (2004) clarify that verb tense or tense agreement and voice are essential for text cohesion, but the inconsistent use of tenses is common type of errors in L2 academic writing like in the following example: Last quarter, the student studied hard, and he gets good grades, the student shifts from the past to the present. This is what Cook (1989, p.15) clarifies by stating that "the form of the verb in one sentence can limit the choice of the verb form in the next". We say that a form is not appropriate because it does not fit with the form in another like in the previous example.

\subsubsection{Parallelism}

Parallelism, for Trimmer (1995, p 196) occurs when two or more elements have the same form. For instance, "he is without a job, without money, without opportunity, without hope" is a parallel sentence in which the four sentences have the same form (they start with without) and the same grammatical function (all of them complete the verb was). Parallel elements may be single words, phrases, clauses or sentences, but coordinate nouns with adjectives, or phrases with clauses; since doing this produces awkwardness. Thus, all members should have the same form or serve the same grammatical function. Oshima and Hougue (1999) clarify that parallelism plays an important role in English writing especially in comparison and contrast listing items or ideas. To them, "parallelism means that each item in a list or comparison follows the same grammatical pattern (p.166). In other words, if the first item in a list is a noun, the following item should be a noun too. If it is an infinitive verb phrase, all the others should be infinitive verb phrases, etc.

\subsection{Lexical Cohesion}




\section{Abid Meriem}

It is clarified that lexical cohesion is an essential relation that should be highlighted in order to the cohesive relations' picture to complete. Lexical cohesion is divided into two types: reiteration and collocation, and it is expressed through the selection of vocabulary.

\subsubsection{Reiteration}

Reiteration is the repetition of the same lexical item or a different lexical item that is related to the first one. MaCarthy (1991, p. 65) states that "reiteration means either restating item in a later part of the discourse by direct repetition or else reasserting its meaning". It is established through the repetition of lexical item, to Oxford Dictionary (2005, p.1285) repetition is defined as the fact of doing or saying the same thing many times; the use of synonyms, for Saeed (1997, p.65), "synonyms are different phonological words which have the same or very similar meanings (...) [such as] coach/sofa, boy/lad, lawyer/attorney, toilet/lavatory, large/big; superordinate term which is the upper term in the inclusion relation hyponymy. This relation is concerned with members of class that are called co-hyponyms. For example, flower is superordinate term for tulip and rose. Animal is the superordinate for lion, elephant; and general words which are on the borderline between lexical items and substitutes, but there is no clear cut between substitutes and general words.

\subsubsection{Collocation}

Collocation is defined in Oxford Dictionary $(2005$, p.293) as "a combination of words in a language that happen very often and more frequently than words happen by chance". To Woolard $(2005$, p.6) collocation is the grammar of words. Fan (2009) clarifies that collocation is defined as the co-occurrence of two or more words in a specific context. Furthermore, Palmer (1981) introduces idiomatic expressions and phrasal verbs as special cases of collocation. Its meaning is idiosyncratic and opaque and cannot be predicted in terms of meaning associated with the words. He also introduces partial idioms where one word has a usual meaning and the other is related to a particular sequence. For instance, red hair refers to hair that is not red in a strict color. Thus, to him, the problem of idiomaticity is a matter of degree.

\section{The Explicit Teaching}

Ellis (2009) clarifies that explicit language leaning is an aware, conscious, and intentional process. In other words, learners are aware of what they have learned and they can verbalize what they have learned. There are two types of awareness: noticing and metalinguistic awareness. The former has to do with perception; it involves conscious attention to surface elements whereas the latter deals with the analysis; it involves awareness of the underlying abstract rule that governs a particular language phenomenon. Tally and Huiling (2001) argue that in explicit teaching, teachers give students rules to practice and make conscious 
efforts to learn. Explicit or direct teaching can be done by applying some learning strategies like selecting attention, activating prior strategies, summarizing, questioning and making inference. To Chamot (2004), explicit teaching involves the development of students' awareness of the strategies they use, teach modeling of strategic thinking, students practice with new strategies, students' self-evaluation of the strategies used, and practice in transferring strategies to new tasks.

Starting from the different definitions and the proposed teaching methods, the explicit teaching discussed in this study (i.e, the explicit teaching of cohesion) goes through four phases:

- Teachers' explanation and presentation of what cohesion is.

- Cohesion's guided practice using different tasks.

- Independent practice accompanied by feedback.

- The application of the cohesion in real situations, i.e., writing essays.

\subsection{Teachers' explanation and presentation of what cohesion is.}

Under this stage, the teacher introduces the term to the students and asks them about their prerequisite skills and knowledge. He should use different examples to clarify what it means. Also, the goal of its use and its role in linking different sentences should be highlighted.

\subsection{Cohesion's guided practice using different tasks.}

To introduce the concept of cohesion to students, we have a variety of tasks. Lee (2002) states that teaching cohesion requires a set of procedures to be followed. First, students should be introduced to the topic using tasks which stimulate their interest. After, they should be given reading handouts about cohesion; its purpose is consolidating students' interest. Later, they should be involved in cohesion awareness-raising tasks using reading texts, analyzing cohesive features and revising texts to improve its cohesive ties. This task can be followed with writing and rewriting activities where students are allowed to use cohesion in their subsequent writings. To Nation (2009) intensive reading is an important way to teach different cohesive devices in context. He insists on teaching activities rather than providing practices helps in developing comprehension and makes the learning process faster and surer. Maintaining this does not require adapted texts; such exercises can be applied to any text.

\subsection{Independent practice accompanied by feedback.}

Hyland (1996, p.177) clarifies that feedback provides opportunities for students to see how others respond to their work and to learn from these responses. This kind of feedback is formative aiming at developing students' writing and consolidating leaning. Generally, there are three kinds of feedback: 


\section{Abid Meriem}

teachers' written feedback, teacher-students conferencing and peer feedback. To Harmer (2004), the most common ways of corrections are underlining, crossing out, question marks and occasional tick. But, for him, this kind of correction is not effective; there are more effective ways such as selective correction where the teacher focuses only on specific aspect such as: verb tense, punctuation, or words order. This kind of feedback is very helpful because it focuses on one aspect only (reference for example), and this is the one used in this study.

\subsection{The Application of the Cohesion in Real Situations ( in Essays)}

This is the stage where students try to apply what they have learned before in the three types of assays: example, comparison and contrast as well as cause and effect. Students are either given specific topics or asked to choose ones of their own. In fact, different aspects of cohesion are given equal importance and introduced explicitly to learners.

Having reviewed previous studies on cohesion and its explicit teaching, this study is conducted to answer the following questions:

1. Do students know what grammatical and lexical ties are? If yes, are they able to use them effectively?

2. Are students able to link sentences together in order to form a coherent discourse?

3. Does teachers' explicit teaching enhance cohesion in students' writing?

In the light of these research questions, we hypothesize:

The explicit teaching of grammatical and lexical cohesive devices would enhance second year students' cohesion.

\section{Methodology}

\subsection{Participants}

This empirical study took place in the Department of English, the University of Mentouri, Constantine 1. Two groups of second year students of English were involved, an EXP and a CTR groups, twenty-five (25) students in each group. The number of participants in each group was larger, but some papers were eliminated from the study because of their writers' absences either during the time of the instruction or on the day the pre- test post-test was administered. In the department, the groups are formed randomly, and this saves us the random sampling which is necessary in similar experimental studies.

\subsection{Data Collection Procedure}


To tap into students' awareness of grammatical and lexical cohesive ties prior to and after instruction, the CTR group and the EXP group were subjected to a pre-test and a post-test. During the pre-test they were asked to write an essay about the advantages of mobile phone usage among teenagers; we made sure not to let the students know that their performance is for this study in order not to exert pressure on them. In the post-test, the participants of both groups are asked to write an essay about "the reasons for having a weak educational system in Algeria", taking into consideration all what they have learned about different types of essays and mainly cohesion during the time of the instruction. They have been supplied with a checklist which served as a reminder of the various cohesive ties they are supposed to realize in their texts.

\subsection{Data Analysis Procedures and Results}

To score the pre-test and post-test papers, we used an analytic approach proposed by Chiang (1999). Though the scale was helpful to score the papers, we did not use it as it is; some modifications were added (appendix). The scoring process happened on eight levels as follows:

\begin{tabular}{|l|l|}
\hline Criteria & marks \\
\hline Reference & 1 to 5 \\
\hline Substitution & 1 to 5 \\
\hline Ellipsis & 1 to 5 \\
\hline Conjunction & 1 to 5 \\
\hline verb agreement & 1 to 5 \\
\hline Parallelism & 1 to 5 \\
\hline reiteration & 1 to 5 \\
\hline collocation & 1 to 5 \\
\hline total & 40 \\
\hline
\end{tabular}

Table 1: Numerical Rating of the Cohesive Ties under Study

Afterwards, the obtained mark for each criterion is added to the pre- and post- tests cohesion score for each participant to obtain the final mark of cohesion. The results are showed in table 2 below: 
Abid Meriem

\begin{tabular}{|c|c|c|c|c|}
\hline \multirow[b]{2}{*}{ Participants } & \multicolumn{2}{|c|}{ EXP group } & \multicolumn{2}{|c|}{ CTR group } \\
\hline & Pre-test & Post-test & Pre-test & Post-test \\
\hline 01 & 16 & 23 & 26 & 24 \\
\hline 02 & 17 & 32 & 24 & 26 \\
\hline 03 & 28 & 30 & 22 & 20 \\
\hline 04 & 22 & 27 & 20 & 19 \\
\hline 05 & 19 & 24 & 17 & 23 \\
\hline 06 & 15 & 30 & 20 & 22 \\
\hline 07 & 16 & 26 & 16 & 19 \\
\hline 08 & 14 & 22 & 15 & 19 \\
\hline 09 & 19 & 23 & 18 & 21 \\
\hline 10 & 21 & 29 & 19 & 22 \\
\hline 11 & 17 & 29 & 21 & 20 \\
\hline 12 & 20 & 29 & 20 & 18 \\
\hline 13 & 20 & 27 & 16 & 23 \\
\hline 14 & 23 & 24 & 15 & 20 \\
\hline 15 & 18 & 30 & 19 & 21 \\
\hline 16 & 20 & 24 & 16 & 22 \\
\hline 17 & 14 & 30 & 19 & 23 \\
\hline 18 & 19 & 21 & 16 & 21 \\
\hline 19 & 16 & 25 & 18 & 24 \\
\hline 20 & 19 & 21 & 16 & 21 \\
\hline 21 & 22 & 25 & \begin{tabular}{|l|}
15 \\
\end{tabular} & 24 \\
\hline 22 & 17 & 30 & 14 & 19 \\
\hline 23 & 16 & 23 & 18 & 22 \\
\hline 24 & 17 & 20 & 14 & 21 \\
\hline 25 & 18 & 28 & 19 & 18 \\
\hline The Means & 18.52 & 27.08 & 18.12 & 21.28 \\
\hline
\end{tabular}

Table 2: Pre- and Post- Tests Scores

In the Pre-test, the score mean of the EXP group is 18.52 higher than the one of the CTR group but still the difference is slight only 0.42 . However, in the post-test, the difference between the two means increased to 5.8 because the mean of the EXP group is 27.08 and that of the CTR group is 21.28. Moreover, an independent $\mathrm{t}$-test is used to check whether the differences between the preand post-tests of the two groups are statistically significant as shown in table 3 . 
The Role of Explicit Teaching Remedy in Enhancing Grammatical and Lexical Cohesive Devices Problem in Second Year Students Writing's at the University of Constantine 01

\begin{tabular}{|l|l|l|l|l|l|l|}
\hline Groups & N & Mean & $\begin{array}{l}\text { Std. } \\
\text { deviation }\end{array}$ & T & df & Sig. \\
\cline { 1 - 5 } EXP group & 25 & 7.4 & 18.24 & 3.89 & 48 & $\begin{array}{l}2.02 \\
\text { P }<0.05\end{array}$ \\
\hline CTR group & 25 & 3.24 & 9.19 & & & \\
\hline
\end{tabular}

Table 3: The Independent t-test for Cohesive Devices

As the above table shows, the obtained t value is 3.89 higher than the critical value 2.02, with the degree of freedom $\mathrm{df}=48$ and the level of significance $\mathrm{p}<0.05$ for the two- tailed hypothesis. Hence, the above stated hypothesis is confirmed.

In what follows, we attempt to analyze the improvements of the two groups in each aspect separately through the comparison of the results they got in each aspect in the pre- and post-tests. This comparison allows us to know the aspects of cohesion which improved more in the paper of EXP group compared to those of the CTR group; to know which aspects have not improved; to know the aspects which have the same improvements in the two groups. Knowing these things enables us to figure out the significance of the proposed method as well as the weaknesses that require further modifications. Below is a table that illustrates the improvement mean of each aspect separately.

\begin{tabular}{|l|l|l|}
\hline Aspects & EXP group & CTR group \\
\hline Reference & 1.92 & 0.96 \\
\hline Substitution & 00 & -0.16 \\
\hline Ellipsis & 0.56 & -0.04 \\
\hline Conjunctions & 1.88 & -0.72 \\
\hline Verb agreement & 0.86 & 0.16 \\
\hline Parallelism & 0.88 & 00 \\
\hline Reiteration & 1.04 & 0.44 \\
\hline Collocation & 0.52 & -0.22 \\
\hline The mean & 7.66 & 2.3 \\
\hline
\end{tabular}

Table 4: Descriptive Information about Improvement Means per Aspect

According to the above table, the most remarkable difference is that, there is no aspect which got an improvement score below the zero in the EXP group, and only one aspect scored equal to zero (substitution), whereas in the CTR group, four aspects (substitution, ellipsis, conjunctions, and collocation) scored below the zero, one aspect equals to zero (parallelism), two others received insignificance progress ( verb agreement, and reiteration), while another one (reference) developed significantly.

\section{The Interpretation of the Results}

The results revealed that the hypothesis sated earlier at the beginning of this research, the explicit teaching of grammatical and lexical ties would enhance 


\section{Abid Meriem}

second year students' writing, is confirmed. During the pre-test, it seems that the two groups have approximately the same level; however, after the treatment the improvement in EXP group is far higher than the CTR group. This is statistically confirmed by the independent t-test 3.89 higher than the critical value 2.02 which means again that the proposed method can be a remedy to cohesive devices problem in second year students' essays.

The study, furthermore, revealed that the improvement appears in the two groups but still there are some aspects which are problematic to students in both groups. In the EXP group, on the one hand, substitution got an improvement score which equals to zero (0), and this is may be contributed to limited use of that aspect in the written papers generally, or because students still do not know its different uses, and more extra explanation should be given. On the other hand, in the CTR group, substitution, ellipsis, conjunctions, parallelism, and collocation got the scores $-0.16,-0.04,-0.72,00$, and -0.22 respectively. The problem can be due to the already stated explanations. Thus, the explicit teaching of such ties may help and can attract the students' attention to an important area which they are neglecting.

In this study, we used tasks, text-prompts, selective feedback as other means to reinforce the understanding of cohesive devices explicitly. In other words, when a variety of tasks are devoted to specific ties, then text-prompts are used to be analyzed or read to verify the wrong and the right uses of different already explained ties, and selective feedback using the red color for instance to correct those devices, these are different strategies to inform the students explicitly about the various grammatical and lexical devices that they may encounter.

\section{Conclusion}

Generally speaking, lack of cohesion is a problem that cannot be ignored. The findings of this study confirmed the hypothesis stated at the very beginning: the explicit teaching of different ties would enhance cohesion in second year students' writing; this hypothesis is also confirmed by the results of the independent $t$ - test. The obtained conclusion can push teachers forward to create new innovative strategies for the application of explicit teaching.

\section{References}

Chiang, S.Y. (1999). Assessing Grammatical and Lexical Features in L2 Writing Samples: The Case of French as a Foreign Language. The Modern Language Journal 83 (ii), 219- 232.

Chamot, A. U. (2004). Issue in Language Learning Strategy Research and Teaching. Electronic Journal for Foreign Language Teaching, 1(1), 14- 26.

Cook, G. (1989). Discourse. Oxford: Oxford University Press.

Ellis, R. (2009). Task Based Language Learning and Teaching. Oxford: Oxford University Press. 
Fan.M. (2009). An exploratory study of collocation use by ESL students: A task based approach, 37-110.

Flowerdrew, J. (2013). Discourse in English language education. Routledge: London.

Halliday, M.A.K. (1994). An introduction to Functional Grammar. London: Edward Anold.

Halliday, M.A.K. \& Hassan, R. (1976). Cohesion in English. London: Longman.

Harmer.G. (2004) . How to Teach Writing. Harlow: Longman.

Hinkel. E. (2004). Teaching Academic ESL Writing. Lawrence Erlbaum Association: Mahwah.

Hyland. K. (1996). Second Language Writing. J. C. Richardes (ed). Cambridge: Cambridge University Press.

Lee. I. (2002). Teaching Coherence to ESL Students: a classroom inquiry journal of language writing, 11, 135- 159.

McCharthy. M. (1991). Discourse Analysis for Language Teachers. Cambridge: Cambridge University Press.

Nation, I.S.P. (2009). Teaching ESL/EFL Reading and Writing. Routledge: New York.

Oshima, A \& Hogue, A. (1999). Writing Academic English. London: Longman.

Saeed, J.I. (1997). Semantics. Oxford: Blackwell Publishers.

Oxford Dictionary. (2005). Oxford: Oxford University Press.

Palmer, F.R. (1981). Semantics. Cambridge: Cambridge University Press.

Tally. P.C. \& Huiling. T. (2014). Implicit and Explicit Teaching of English Speaking in the EFL Classroom 4 (6). International Journal of Humanities and Social Sciences, 38-46.

Trimmer, J.F. (1996). Writing with a Purpose. Boston: Toranto.

Widdowson, H.G. (2007). Discourse Analysis. Oxford: Oxford University Press.

Yule, G. (1996). Pragmatics. Oxford: Oxford University Press.

Zamel, V. (1983). Teaching those missing links in writing. ELT Journal, 2229.

\section{Appendix}

Chiang (1999, p.221-192) introduces a rating scale for assessing writing in general and cohesion in specific. This scale consists of statements describing the degree sentences are related to each other. The scale is made of nine constituents ranging from (a) to (i); each of which needs to be scored from 1 to 5 depending on the students' performance, but in case insufficient or no information are available concerning a particular feature, the rater circles not applicable (NA). In this study Chiang's scale is not used as it is, some modifications are made as follows: 
Please circle the number that reflects the degree to which you agree with the statement about the essay. Circle NA (Not Applicable) when insufficient or no information is available concerning the particular feature.

$5=$ Strongly Agree $4=$ Agree $3=$ Undecided $2=$ Disagree $1=$ Strongly Disagree

\section{COHESION}

54321 NA (a) The exact same vocabulary/expressions/structures are repeated consistently, and equivalent words/paraphrases, when used, are used appropriately.

54321 NA (b) Pronouns of reference are used appropriately and accurately.

54321 NA (c) Ellipsis is used where needed.

54321 NA (d) Where no junction words are used, transition between sentences is smooth.

5432 1NA (e) words collocate together in a good and harmonious way.

54321 NA (f) subject-verb- agreement.

$54321 \mathrm{NA}(\mathrm{g})$ parallel structures are used appropriately and accurately.

$54321 \mathrm{NA}(\mathrm{h})$ verbs are used in the appropriate tenses and there is no shift from one tense to another only when needed. 